\title{
IMPACT OF NON-SURGICAL PERIODONTAL THERAPY ON VISFATIN LEVEL IN GINGIVAL CREVICULAR FLUID OF TYPE II DIABETIC PATIENTS WITH PERIODONTITIS
}

\author{
Yasser M. El Makaky * and Hany K.Shalaby **
}

\begin{abstract}
Background: Visfatin was reported to exert various pro-inflammatory function. The present study aims to evaluate the level of visfatin in gingival crevicular fluid (GCF) and assess this relationship in individuals with diabetes mellitus type 2 (T2DM) and periodontitis (P) before and following nonsurgical periodontal therapy (NSPT).

Patients and methods: Forty-five subjects were enrolled in this study and equally divided into three groups, group 1: healthy participants, group 2: patients with diabetes mellitus (T2DM) and periodontitis and group 3: patients with periodontitis only. Clinical parameters were recorded at baseline and after NSPT at 1,3 and 6 months, visfatin levels were also assessed at the same time intervals using enzyme-linked immunosorbent assay.
\end{abstract}

Results: GCF visfatin level at baseline showed a significantly lower concentration in healthy participants than in patients with periodontitis and T2DM and those with periodontitis only. A significant reduction in GCF visfatin level was observed in groups 2 and 3 following NSPT at 1 , 3 and 6 months.

Conclusion: The non-surgical periodontal therapy can significantly reduce GCF visfatin levels in patients with T2DM and periodontitis and those with only periodontitis. Furthermore, visfatin may be suggested as an inflammatory marker for periodontitis.

KEYWORDS: Periodontitis; Visfatin; Gingival crevicular fluid; Diabetes mellitus; Nonsurgical periodontal therapy.

\section{INTRODUCTION}

Periodontal disease can be defined as a chronic inflammatory disorder initiated by piling up of dental plaque in the gingival sulcus causing an inflammatory response (Nikolopoulos et al., 2008). The periodontopathogens and their products cause the local host response in the form of macrophages proliferation and release of cytokines. These chemical immune mediators

\footnotetext{
* Assistant Professor of Periodontology and Oral Medicine, Faculty of Dentistry, Tanta University, Egypt

** Assistant Professor of Periodontology and Oral Medicine, Faculty of Dentistry, Suez Canal University, Egypt
} 
are thought to play a pivotal role in periodontitis. Various pro-inflammatory cytokines such as tumor necrosis factor (TNF)- $\alpha$ and interleukin (IL)- $1 \mathrm{~b}$ are determinants of the periodontitis progression (Graves \& Cochran, 2003). Moreover, disease severity and loss of supporting periodontal tissues appear to be correlated with increased circulating IL-6 levels (Mengel et al., 2002).

Many of these chemical mediators have been proposed to be utilized as biomarkers for periodontal disease activity assessment because the concentration of these mediators changes with the progression of periodontal disease (Buduneli $\&$ Kinane, 2011). One of these mediators that have already been linked with diabetes mellitus type 2(T2DM) and in the recent past, has been associated with periodontal disease is visfatin (Pradeep et al., 2011).

It has been shown that periodontitis may impact systemic health (Iacopino \& Cutler, 2000). Additionally, periodontitis is associated with obesity and diabetes (Devanoorkar et al.,2014), and patients with metabolic syndrome or obesity have an increased risk for periodontal diseases (Saito \& Shimazaki, 2007). However, the biological mechanism between periodontitis and glycometabolism is little known. Adipose tissue is an endocrine organ, that helps in energy homeostasis and, also secretes active substances includes adipokines which are hormonelike proteins, involving plasminogen activator inhibitor 1, visfatin, leptin, and proinflammatory cytokines (Garlet et al., 2006). These cytokines and factors are thought to affect immune responses, insulin resistance, and play a role in inflammation (Fantuzzi, 2005).

Visfatin is an enhancing factor for the pre-B cell colony which consider among different species as highly conserved protein (Ray, 2012). Additionally, Visfatin is homologous in function and sequence significantly with nicotinamide phosphoribosyl transferase, that is an important enzyme in the biosynthesis of nicotinamide adeninedinucleotide (Chen, 2002), which share in the procedure of cellular respiration within all living cells and Zhou et al. concluded that nicotinamide overload may implicate in (T2DM) development (Zhou et al., 2009).

The pro-inflammatory cytokines like IL$1 \mathrm{~b}$ and IL-6 can be upregulated by periodontal inflammation, which in turn causes high expression of visfatin within periodontium (Nokhbehsaim et al., 2013). A higher level of visfatin has been expressed in both gingival crevicular fluid (GCF) and serum of subjects with chronic periodontitis (CP), than individuals with healthy periodontium (Pradeep et al., 2012), and has been reduced following non-surgical periodontal therapy (Raghavendra et al., 2012). However, the level of visfatin in GCF and serum in diabetic patients with $\mathrm{CP}$ prior and following non-surgical periodontal therapy has not been searched extensively (Wu et al.,2015). Therefore, this trial aims to study the effect of nonsurgical periodontal therapy on the level of visfatin in GCF in diabetic patients with periodontitis (P) and assess the hypothesis that visfatin is a diagnostic biomarker for progression of periodontal diseases and presence of T2DM.

\section{MATERIAL AND METHOD}

\section{Study participants:}

In the present study, a total of 45 patients (22 females and 23 males females; age range: 25 to 45 years) were recruited from the Internal Medicine Outpatients Clinic and Periodontology Department, Suez Canal University from April 2017 to March 2018. All patients who agreed to participate in this trial signed informed consent and the study protocol was clearly stated to all participants. This clinical study was conducted on three parallel groups with six months follow up period.

Group 1: included 15 participants with a healthy periodontium. 
Group 2: composed of 15 patients with $\mathrm{P}$ and T2DM.

Group 3: consisted of 15 patients with P.

\section{Inclusion criteria:}

- $\quad$ Age from 25 to 45 years

- Minimum 20 permanent teeth

- Diagnosis of T2DM for more than one year

- No change in diabetes medications over the last three months

- No Periodontal treatment in the last six months

- No history of nonsteroidal anti-inflammatory medications in the last six months

- Diagnosis of periodontitis depends on the new classification of periodontitis (Tonetti et al., 2018), were as follows: Generalized or localized periodontitis of stage I, II, or III with grades A, $\mathrm{B}$ or $\mathrm{C}$.

- Clinically healthy periodontium was defined regarding the new classification of periodontal diseases. Gingival index $(\mathrm{GI})=0$ with probing pocket depth (PPD) $\leq 3$ and clinical attachment loss $(\mathrm{CAL}) \leq 3 \mathrm{~mm}$.

\section{Exclusion criteria:}

- Tobacco use in any form either current or former

- Any systemic disorders that affect the course of periodontitis such as immune disease, cardiovascular disease, malignant tumors, etc.

- Pregnancy or breastfeeding

- A history of receiving systemic antibiotics or anti-hyperlipidemic agents during the last 6 months.

- A history of periodontal therapy in the last 6 months

\section{Intervention protocol}

Patients in groups 2 and 3 received periodontal therapy in the form of a single session of full-mouth scaling, and root planing (SRP), while those in group 1 were given only oral hygiene instructions (OHI). Gracey curettes (Hu-Friedy, Chicago, IL, USA) and ultrasonic apparatus (Cavitron Select SPC, Dentsply professional, New York, USA) were used by the same specialist to perform this periodontal treatment at 1,3 and 6 months when needed Local anesthesia was used. Free dental care products were given to patients to ensure adequate periodontal maintenance throughout the follow-up period. Non-surgical periodontal therapy (NSPT) was not associated with any medications.

\section{Clinical follow-up}

At first, a complete medical history and full-mouth examination were carried out on all participants. They received detailed data about the study protocol if they fit the inclusion criteria. Each tooth was examined by mean of a periodontal probe (Hu-Friedy, Chicago, IL, USA) to measure CAL (distance from cement-enamel junction to pocket base), PPD (Linear measurement from gingival margin to base of sulcus), GI (Löe \& Silness, 1963) ( which is used to assess severity and extent of gingival inflammation), and plaque index (PI) (Silness \& Löe, 1964) at baseline, 1,3, and 6 months. The measurements of this periodontal parameters were performed by the same specialist. Before starting this study to measure the intra-examiner calibration Test-retest exercises were carried out on 18 participants. The reproducibility of the intraexaminer for CAL was $85 \%$ and PD was $80 \%$.

\section{GCF Collection}

The GCF samples were taken a day after recording the periodontal parameters to avoid blood contamination of the samples. GCF samples were taken after breakfast by 2 to 3 hours in the morning. The air syringe and cotton rolls were used to isolate and dry sites to be sampled. Paper strips (Whatman Paper, Little Chalfont, UK) were inserted gently into the gingival sulcus till a little 
resistance was felt and placed for 30 seconds. All samples contaminated with blood were discarded. The volume of GCF in each strip was calculated by a Periotron 6000 (Proflow Inc., Amityville, NY, USA). Immediately, after collection procedure, the samples were moved to microcentrifuge tubes and stocked at $-70^{\circ} \mathrm{C}$ until analyzed. GCF samples were collected at baseline and after1, 3, and 6 months from all study populations.

\section{Biochemical Assay}

Visfatin concentration in samples was assayed by a commercially available Visfatin Enzyme Immunoassay kit (Visfatin Enzyme Immunoassay, Ray Biotech, Norcross, GA) according to the manufacturer's prescript. The biochemical assay was carried out on the Department of Microbiology, Faculty of Medicine, Suez Canal University, Egypt. All reagents were conditioned at room temperature $\left(18-25^{\circ} \mathrm{C}\right)$ for at least 30 minutes prior to use. The kit had anti-visfatin antibodies with a minimum detection sensitivity of $<0.25 \mathrm{ng} / \mathrm{mL}$. It was recommended based on the manufacturer's instructions that all samples and standards turn on at least in duplicate. The final step in the enzymelinked immunosorbent assay (ELISA) was the addition of a $50 \mathrm{~mL}$ stop solution to each well, and after 10 minutes an ELISA reader (Molecular Dynamics, Sunnyvale, CA) was used to read the absorbance of the substrate color reaction under $450 \mathrm{~nm}$ wavelength. The total amount of visfatin was determined using nanograms, and the concentration of visfatin in each sample was computed by dividing the visfatin amount on the GCF volume of the sample. The concentration of visfatin was recorded as nanograms per milliliter $(\mathrm{ng} / \mathrm{mL})$ in each sample.

\section{Study outcomes}

The primary outcome in this study was a change in the mean values of visfatin concentration between the different studied groups throughout the followup period. While, secondary outcomes were changes in mean values of periodontal parameters (CAL, PI, GI, and PPD) between the different groups at evaluation periods.

\section{Statistical analysis}

Data were tabulated, collected, coded, and then the SPSS software version 17.0 was used to analyze this data. Descriptive statistics were calculated using Mean \pm Standard deviation (SD) and Median \&Interquartile range (IQR), followed by analytical statistics using :

- One way ANOVA that applied to compare between $>$ two different studied groups of parametric numerical data followed by post-hoc Tukey.

- Analysis of variance (Repeated measure ANOVA) that used to compare between more than two related groups of parametric numerical data followed by post-hoc Bonferroni.

- Kruskal Wallis test: apply to compare between more than two different groups of nonparametric numerical data followed by post-hoc Dunn's.

- Friedman test: used to compare between more than two related groups of numerical (non-parametric) data followed by pairwise comparisons.

P-value was considered to be statistically significant when it was $\leq 0.05$.

\section{RESULTS}

At initial enrolment, 93 participants were evaluated for eligibility. Subsequently, stratifying exclusion and inclusion criteria, 45 patients were met the inclusion criteria, enrolled in the studied groups and then received the allocated intervention. No one of the patients in group 2 and group 3 shown adverse side effects following the allocated periodontal therapy. All participants in all three studied groups attended all assessment visits.

All secondary outcomes (CAL, PI, GI, and PPD) were shown in Tables 1, and 2. It was demonstrated 
that at baseline and all evaluation periods they were all significantly higher in patients within groups 2 and 3 than participants in group 1 (all $\mathrm{p} \leq 0.05$ ) with no statistically significant differences between groups 2 and 3. After periodontal therapy, withingroup 2 and 3, the mean values of these clinical periodontal parameters were significantly reduced with the time of assessment from baseline to 1,3 , and 6months (all $\mathrm{p} \leq 0.05)$.
In all studied groups, all samples tested positive for visfatin. The mean values of visfatin concentration in GCF $(\mathrm{ng} / \mathrm{mL})$ was presented in Table 3. At baseline and all visits of measurement throughout the study period, Visfatin concentration $(\mathrm{ng} / \mathrm{mL})$ were significantly greater in groups 2 and 3 compared with group 1(all $\mathrm{p} \leq 0.05$ ). They were significantly reduced in groups 2 and 3 after periodontal therapy.

TABLE (1): Comparison of Clinical attachment level \& Probing pocket depth between studied groups

\begin{tabular}{|c|c|c|c|c|c|c|c|}
\hline $\begin{array}{l}\text { Parameters/ follow- } \\
\text { up periods }\end{array}$ & $\begin{array}{c}\text { Group } 1 \\
\text { (participants } \\
\text { with a healthy } \\
\text { periodontium) } \\
\text { n= } 15\end{array}$ & $\begin{array}{c}\text { Group } 2 \\
\text { (Patients with } \\
\text { P+T2DM) } \\
\text { n }=15\end{array}$ & $\mathrm{Z}$ & $\begin{array}{l}\text { Inter-p- } \\
\text { value } \\
\text { Group } 2 \\
\text { vs Normal } \\
\text { group }\end{array}$ & $\begin{array}{c}\text { Group } 3 \\
\text { (Patients with } \\
\text { P) } \\
\mathrm{n}=15\end{array}$ & $\mathrm{Z}$ & $\begin{array}{c}\text { Inter-p-value } \\
\text { Group } 3 \\
\text { Vs normal } \\
\text { group }\end{array}$ \\
\hline \multicolumn{8}{|l|}{ CAL (mm) } \\
\hline Baseline & $0(0-0)$ & $5.5(5.0-5.5)$ & 3.549 & $0.01 *$ & $4.5(4.5-5.0)$ & 3.498 & $0.01 *$ \\
\hline 1Months & $0(0-0)$ & $4.5(4.0-4.5)^{\mathrm{a}}$ & 3.498 & $0.01^{*}$ & $4.0(3.5-4.0)^{\mathrm{a}}$ & 3.434 & $0.01 *$ \\
\hline 3Months & $0(0-0)$ & $4.0(3.5-4.0)^{a b}$ & 3.434 & $0.01 *$ & $3.0(2.5-3.5)^{\mathrm{ab}}$ & 2.125 & $0.04 *$ \\
\hline 6 Months & $0(0-0)$ & $3.0(2.5-3.0)^{\mathrm{abc}}$ & 2.113 & $0.04 *$ & $2.0(2.0-2.5)^{\mathrm{abc}}$ & 2.041 & $0.041^{*}$ \\
\hline $\mathrm{F}$ & 1.00 & 8.856 & & & 8.956 & & \\
\hline $\begin{array}{l}\text { Intra p-value Intra- } \\
\text { group comparison }\end{array}$ & 0.848 & $0.001 *$ & & & $0.001 *$ & & \\
\hline \multicolumn{8}{|l|}{ PPD ( mm) } \\
\hline Baseline & $2.0(1.0-2.5)$ & $6.5(6.0-6.5)$ & 3.569 & $0.02 *$ & $5.5(5.5-6.0)$ & 3.43 & $0.02 *$ \\
\hline 1Months & $2.0(1.0-2.5)$ & $5.5(5.0-6.0)^{\mathrm{a}}$ & 3.431 & $0.02 *$ & $5.0(4.0-5.0)^{\mathrm{a}}$ & 3.252 & $0.01^{*}$ \\
\hline 3Months & $2.0(1.0-2.5)$ & $5.0(4.0-5.0)^{\mathrm{ab}}$ & 3.252 & $0.01 *$ & $4.0(3.5-4.0)^{\mathrm{ab}}$ & 2.98 & $0.04 *$ \\
\hline 6Month & $2.0(1.0-2.5)$ & $4.0(3.5-4.0)^{\mathrm{abc}}$ & 2.86 & $0.04 *$ & $3.0(3.0-3.5)^{\mathrm{abc}}$ & 2.43 & $0.041 *$ \\
\hline $\mathrm{F}$ & 1.00 & 9.098 & & & 9.094 & & \\
\hline $\begin{array}{l}\text { intra p-value Intra- } \\
\text { group comparison }\end{array}$ & 0.848 & $0.001 *$ & & & $0.001 *$ & & \\
\hline
\end{tabular}

Data expressed as median\& range *: significance $P \leq 0.05 \quad n=$ number $\quad Z=$ Kruskal Wallis followed by post-hoc Dunn's. F = Repeated measured ANOVA. Small letters indicate significance between time (a: significance vs Baseline; b: significance vs 1Month; : significance vs 3Month) 
TABLE (2): Gingival index and Plaque index at different periods of follow up

\begin{tabular}{|c|c|c|c|c|c|c|c|}
\hline $\begin{array}{l}\text { Parameters/ follow- } \\
\text { up periods }\end{array}$ & $\begin{array}{c}\text { Group } 1 \\
\text { (participants } \\
\text { with a healthy } \\
\text { periodontium) } \\
\quad \mathrm{n}=15\end{array}$ & $\begin{array}{c}\text { Group } 2 \\
\text { (Patients with } \\
\text { P+T2DM) } \\
\mathrm{n}=15\end{array}$ & $\mathrm{Z}$ & $\begin{array}{l}\text { Inter-p-value } \\
\text { Group } 2 \\
\text { vs Normal } \\
\text { group }\end{array}$ & $\begin{array}{c}\text { Group } 3 \\
\text { (Patients with P) } \\
\qquad \mathrm{n}=15\end{array}$ & $\mathrm{Z}$ & $\begin{array}{l}\text { Inter-p-value } \\
\text { Group } 3 \mathrm{Vs} \\
\text { normal group }\end{array}$ \\
\hline \multicolumn{8}{|l|}{ GI } \\
\hline Baseline & $0(0-0)$ & $2.9(2.5-3.0)$ & 2.045 & $0.04 *$ & $2.5(2.5-3.0)$ & 2.089 & $0.04 *$ \\
\hline 1Months & $0(0-0)$ & $2.0(2.0-2.5)^{\mathrm{a}}$ & 2.041 & $0.041^{*}$ & $2.0(1.8-2.5)^{\mathrm{a}}$ & 2.047 & $0.041^{*}$ \\
\hline 3Months & $0(0-0)$ & $1.0(0.9-1.5)^{\mathrm{ab}}$ & 2.234 & $0.04 *$ & $0.8(0.7-1.0)^{\mathrm{ab}}$ & 2.79 & $0.04 *$ \\
\hline 6 Months & $0(0-0)$ & $0.4(0.3-0.6)^{\mathrm{abc}}$ & 2.032 & $0.01 *$ & $0.3(0.3-0.4)^{\mathrm{abc}}$ & 2.022 & $0.01 *$ \\
\hline $\mathrm{F}$ & 1.00 & 9.899 & & & 9.867 & & \\
\hline $\begin{array}{l}\text { Intra p-value Intra- } \\
\text { group comparison }\end{array}$ & 0.848 & $0.001 *$ & & & $0.001^{*}$ & & \\
\hline \multicolumn{8}{|l|}{ PI } \\
\hline Baseline & $0(0-0)$ & $3.0(3.0-3.0)$ & 2.622 & $0.01 *$ & $3.0(2.0-3.0)$ & 2.622 & $0.01 *$ \\
\hline 1Months & $0(0-0)$ & $2.0(2.0-2.5)^{\mathrm{a}}$ & 2.043 & $0.041^{*}$ & $2.0(1.5-2.0)^{\mathrm{a}}$ & 2.042 & $0.041 *$ \\
\hline 3Months & $0(0-0)$ & $1.3(1.0-1.6)^{\mathrm{ab}}$ & 2.235 & $0.04 *$ & $1.0(0.7-1.0)^{\mathrm{ab}}$ & 2.114 & $0.04 *$ \\
\hline 6Month & $0(0-0)$ & $0.5(0.4-0.7)^{\mathrm{abc}}$ & 2.072 & $0.01 *$ & $0.4(0.3-0.5)^{\mathrm{abc}}$ & 2.032 & $0.01 *$ \\
\hline $\mathrm{F}$ & 1.00 & 8.568 & & & 8.354 & & \\
\hline $\begin{array}{l}\text { Intra p-value Intra- } \\
\text { group comparison }\end{array}$ & 0.848 & $0.001 *$ & & & $0.001 *$ & & \\
\hline
\end{tabular}

Data expressed as median\& range *: significance $P \leq 0.05 \quad n=$ number $\quad Z=$ Kruskal Wallis followed by post-hoc Dunn's. $F=$ Repeated measured ANOVA. Small letters indicate significance between time (a: significance vs Baseline; b: significance vs 1Month; : significance vs 3Month)

TABLE (3): Comparison of Visfatin concentration in gingival crevicular fluid among studied groups

\begin{tabular}{|c|c|c|c|c|c|c|c|}
\hline $\begin{array}{c}\text { Parameters/ } \\
\text { follow-up periods }\end{array}$ & $\begin{array}{c}\text { Group } 1 \\
\text { (participants } \\
\text { with a healthy } \\
\text { periodontium) } \\
\mathrm{n}=15\end{array}$ & $\begin{array}{c}\text { Group } 2 \\
\text { (Patients with } \\
\text { P+T2DM) } \\
\text { n }=15\end{array}$ & $\mathrm{Z}$ & $\begin{array}{l}\text { Inter-p-value } \\
\text { Group } 2 \text { vs } \\
\text { Normal group }\end{array}$ & $\begin{array}{c}\text { Group } 3 \\
\text { (Patients with } \\
\text { P) } \\
\mathrm{n}=15\end{array}$ & Z & $\begin{array}{l}\text { Inter-p-value } \\
\text { Group } 3 \text { Vs } \\
\text { normal group }\end{array}$ \\
\hline \multicolumn{8}{|l|}{ Visfatin (ng/mL) } \\
\hline Baseline & $6.44 \pm 0.86$ & $11.65 \pm 0.83$ & 5.780 & $0.001 *$ & $11.04 \pm 0.70$ & 5.682 & $0.001 *$ \\
\hline 1Months & $6.37 \pm 0.88$ & $10.79 \pm 0.86^{\mathrm{a}}$ & 5.362 & $0.001 *$ & $10.34 \pm 0.74^{\mathrm{a}}$ & 5.363 & $0.001 *$ \\
\hline 3Months & $6.31 \pm 0.87$ & $9.87 \pm 0.87^{\mathrm{ab}}$ & 5.087 & $0.001 *$ & $9.43 \pm 0.81 \mathrm{ab}$ & 5.054 & $0.001 *$ \\
\hline 6 Months & $6.28 \pm 0.89$ & $8.83 \pm 0.93 \mathrm{abc}$ & 4.983 & $0.001 *$ & $8.39 \pm 0.77^{\mathrm{abc}}$ & 4.863 & $0.001 *$ \\
\hline F & 0.978 & 10.138 & & & 10.867 & & \\
\hline $\begin{array}{l}\text { Intra p-value Intra- } \\
\text { group comparison }\end{array}$ & 0.856 & $0.001 *$ & & & $0.001 *$ & & \\
\hline
\end{tabular}

Data expressed as mean \pm standard deviation $\quad *$ : significance $P \leq 0.05 \quad n=$ number $\quad z=$ One-way ANOVA followed by post-hoc Tuky. F = Repeated measured ANOVA. Small letters indicate significance between time (a: significance vs Baseline; b: significance vs 1Month; : significance vs 3Month) 


\section{DISCUSSION}

A small number of clinical trials have assessed the impact of periodontal therapy on visfatin concentration (Nader et al., 2015). The goal of this clinical trial was to evaluate the changes in visfatin concentration in GCF between healthy participants, patients with T2DM and periodontitis, and those with only periodontitis. Moreover, assess the effect of NSPT on the concentration of visfatin in GCF.

In this study design, the impact of gender and age on the GCF visfatin level was minimized by the selection of participants with a specified age range ( 25 to 45 years) and enrolling a nearly equal number of both sexes in the study. Therefore, the variation in visfatin concentration in each group could be caused by the nature and stages of the disease progression at the time of sample collection. This is in accordance with Ghallab et al. who conducted their study on fifty subjects (25 females and 25 males) within a definite age range (35-54 years) (Ghallab et al., 2015), and also Pradeep et al. who selected patients with age range from 23 to 53 years and enrolled an equal number of females and males in their study (Pradeep et al., 2011).

Regarding the primary outcome in this study, the results showed a significant decrease in GCF visfatin concentration after 1, 3, and 6 months of NSPT in groups 2 and 3 . These results were consistent with Raghavendra et al. who evaluated the effect of NSPT on GCF visfatin concentrations after 8 weeks and reported a significant reduction in GCF levels of visfatin following treatment (Raghavendra et al., 2012). This observation also coincided with $\mathrm{Wu}$ et al. who studied the impact of NSPT on Serum and GCF visfatin concentrations at 3 and 6 months postoperatively and observed a significant decrease in visfatin level in serum and GCF (Wu et al., 2015).

The biochemical assay in the present study showed that the visfatin concentration in GCF was significantly higher in patients with periodontitis and those with periodontitis and having T2DM than in participants with healthy periodontium. These results indicated that the level of visfatin in GCF increases proportionately with the disease severity and the variation of GCF visfatin concentration at the time of sample collection of GCF in the participants of each group caused by the role of visfatin in the various stages of disease procedure. A similar observation was reported by Tabari et al. who evaluated salivary visfatin levels in patients with chronic periodontitis and periodontally healthy participants and reported that the salivary level of visfatin was significantly higher in individuals with chronic periodontitis (Tabari., 2014). This also was consistent with Pradeep et al. who studied GCF and serum level of visfatin in patients with gingivitis, chronic Periodontitis, and healthy participants and found that visfatin level was significantly lower in healthy individuals than in those with chronic periodontitis (Pradeep et al., 2011).

In another trial by Pradeep et al. GCF and serum level of visfatin were assessed in type 2 diabetes with chronic periodontitis, patients with chronic periodontitis alone, and periodontally healthy subjects. Serum and GCF visfatin concentration in diabetes having chronic periodontitis and patients with chronic periodontitis only were higher than in healthy individuals. Based on these results, Pradeep et al. concluded that the level of visfatin considered an inflammatory marker for periodontal diseases (Pradeep et al., 2012), which was consistent with the present study. It has been concluded that visfatin has a main role in the inflammation via neutrophils and inhibition of apoptosis. Besides, it has more potent pro-inflammatory and destructive properties (Luk et al., 2008). The concentration of Visfatin enhances in response to IL-1 $\beta$ in chondrocytes and acts in a paracrine and autocrine pattern in the synthesis of prostaglandin E2 (PGE-2)(Gosset et al., 2008).

Visfatin, a 52-kDa adipocytokine encourages the persistence of inflammation via its power to prevent neutrophil apoptosis (Jia et al.,2004) and has been associated with inflammatory disorders such as inflammatory bowel disease (Moschen et al.,2007). Adipokines are supposed to act via their 
impacts on insulin sensitivity, and hence changed levels of these hormones were linked to T2DM (Fantuzzi, 2005). In addition, adipokines have been demonstrated to have a role in the pathogenesis of T2DM and periodontitis (Ogawaet al.,2014).

Visfatin was reported to be a robust chemotactic factor that stimulates pro-inflammatory cytokine formation by human leukocytes (Buldak et al.,2013). Schilling et al. found that Fusobacterium nucleatum can increase the production of visfatin from periodontal ligament cells (Schilling et al.,2012). So, inflammatory mediators and bacteria may utilize this adipokine for their damaging impacts on periodontal tissues (Deschner et al.,2014). These studies hypothesize that visfatin might associate with periodontal disease pathogenesis via their role in local immunoinflammatory responses in the periodontium.

Similarly, Ghallab et al. who assessed expression of both visfatin and Leptin in gingival tissues from healthy participants, patients with chronic periodontitis only, and patients having chronic periodontitis and T2DM utilizing realtime polymerase chain reaction and enzyme-linked immunosorbent assay and showed significantly higher expression of visfatin in chronic periodontitis + T2DM group and chronic periodontitis group compared with healthy group.

The clinical results of this study showed that the mean values of the following periodontal parameters; PI, GI, PPD, and CAL significantly decreased following the allocated periodontal therapy in groups 2 and 3 at 1, 3, and 6 months postoperatively. Our results propose that nonsurgical periodontal therapy (NSPT) was a successful and improved periodontal condition. This in consistent with Chen et al. who studied the effect of SRP on 134 diabetic patients with chronic periodontitis and found that NSPT could significantly improve circulating inflammatory and periodontal status ( Chen et al., 2012). A similar observation was showed by Quintero et al. who investigated the effect of either multi-session or onestage NSPT modality in diabetic and non-diabetic patients with chronic periodontitis; these findings demonstrated that both techniques were equally provided significant periodontal clinical parameter improvements (Quintero et al., 2018).

Following $\mathrm{Wu}$ et al. in this trial, an important side was an intervention of an NSPT in groups 2 and 3 versus no active periodontal therapy in group 1 to increase the probability to study any effect of the allocated intervention on visfatin level (Wu et al., 2015). In the present study, GCF samples were taken as GCF reflects the condition of periodontium more properly because it is in ultimate contact with this tissue. This is in contrast with Todorovic et al. and Nader et al. who used salivary samples. Also, they reported that it is difficult to sample GCF and salivary specimens can be taken without a need for special skills (Todorovic et al., 2006; Nader et al., 2015). Paper strips were utilized in the present trial to collect GCF samples which provide the following advantages; low cost and did not cause any inconvenience for the patients. This is in accordance with Wu et al. who used paper strips for GCF and blood collection (Wu et al., 2015).

Thus, the concentration of visfatin in GCF can be counted as a potential marker for the activity of the inflammatory process in periodontal disease. Hence, the progression of periodontal disease might help in predicting high-risk peoples for the most prevalent diseases of the present era like diabetes and cardiovascular disorders. Furthermore, periodontal treatment might reduce the riskiness of these systemic disorders because it lowers the inflammatory load in both medically compromised and healthy peoples.

The current trial has some limitations. First, the follow-up period is relatively short. Second, if microbiological analysis and the biochemical assay had been performed at the same time, the findings of the study might be more convincing. Therefore, additional longitudinal prospective trials 
with a longer duration and larger total sample size in various populations are needed to confirm the outcomes of the current trial and to consider the level of visfatin in GCF as an inflammatory biomarker for periodontal diseases and to better understand the exact role of visfatin in periodontitis process.

\section{CONCLUSIONS}

Within the limitations of the current trial, the outcomes of this study concluded that:

- The GCF visfatin concentration in healthy participants was significantly lower than that in type 2 diabetic patients with periodontitis and in those with periodontitis only. Thus, visfatin concentration in GCF can be suggested as an inflammatory marker in periodontitis and T2DM.

- The NSPT caused a significant reduction of GCF visfatin concentration in type 2 diabetic patients having $\mathrm{P}$ and patients with periodontitis only

\section{REFERENCES}

1. Buduneli, N., \& Kinane, D. F. (2011). Host-derived diagnostic markers related to soft tissue destruction and bone degradation in periodontitis. Journal of clinical periodontology, 38, 85-105.

2. Buldak, R. J., Polaniak, R., Buldak, L., Mielanczyk, L., Kukla, M., Skonieczna, M., ... \& Zwirska-Korczala, K. (2013). Exogenous administration of visfatin affects cytokine secretion and increases oxidative stress in human malignant melanoma Me45 cells. J Physiol Pharmacol, 64(3), 377-85.

3. Chen, H. (2002). Evidence that the diabetes gene encodes the leptin receptor: identification of a mutation in the leptin receptor gene in $\mathrm{db} / \mathrm{db}$ mice. Developmental Cell, 2, 497-503.

4. Chen, L., Luo, G., Xuan, D., Wei, B., Liu, F., Li, J., \& Zhang, J. (2012). Effects of non-surgical periodontal treatment on clinical response, serum inflammatory parameters, and metabolic control in patients with type 2 diabetes: A randomized study. Journal of periodontology, 83(4), 435-443.
5. Devanoorkar, A., Kathariya, R., Guttiganur, N., Gopalakrishnan, D., \& Bagchi, P. (2014). Resistin: a potential biomarker for periodontitis influenced diabetes mellitus and diabetes induced periodontitis. Disease markers, 2014.

6. Deschner, J., Eick, S., Damanaki, A., \& Nokhbehsaim, M. (2014). The role of adipokines in periodontal infection and healing. Molecular oral microbiology, 29(6), 258-269.

7. Fantuzzi, G. (2005). Adipose tissue, adipokines, and inflammation. Journal of Allergy and clinical immunology, 115(5), 911-919.

8. Garlet, G. P., Cardoso, C., Silva, T., Ferreira, B., ÁvilaCampos, M. J., Cunha, F. d. Q., \& Silva, J. S. d. (2006). Cytokine pattern determines the progression of experimental periodontal disease induced by Actinobacillus actinomycetemcomitans through the modulation of MMPs, RANKL, and their physiological inhibitors. Oral microbiology and immunology, 21(1), 12-20.

9. Ghallab, N. A., Amr, E. M., \& Shaker, O. G. (2015). Expression of leptin and visfatin in gingival tissues of chronic periodontitis with and without type 2 diabetes mellitus: a study using enzyme-linked immunosorbent assay and realtime polymerase chain reaction. Journal of periodontology, 86(7), 882-889.

10. Gosset, M., Berenbaum, F., Salvat, C., Sautet, A., Pigenet, A., Tahiri, K., \& Jacques, C. (2008). Crucial role of visfatin/pre-B cell colony-enhancing factor in matrix degradation and prostaglandin E2 synthesis in chondrocytes: Possible influence on osteoarthritis. Arthritis \& Rheumatism, 58(5), 1399-1409.

11. Graves, D. T., \& Cochran, D. (2003). The contribution of interleukin-1 and tumor necrosis factor to periodontal tissue destruction. Journal of periodontology, 74(3), 391-401.

12. Iacopino, A. M., \& Cutler, C. W. (2000). Pathophysiological relationships between periodontitis and systemic disease: recent concepts involving serum lipids. Journal of periodontology, 71(8), 1375-1384.

13. Jia, S. H., Li, Y., Parodo, J., Kapus, A., Fan, L., Rotstein, O. D., \& Marshall, J. C. (2004). Pre-B cell colony-enhancing factor inhibits neutrophil apoptosis in experimental inflammation and clinical sepsis. The Journal of clinical investigation, 113(9), 1318-1327.

14. Löe, H., \& Silness, J. (1963). Periodontal disease in pregnancy I. Prevalence and severity. Acta odontologica scandinavica, 21(6), 533-551. 
15. Luk, T., Malam, Z., \& Marshall, J. C. (2008). Pre-B cell colony-enhancing factor (PBEF)/visfatin: a novel mediator of innate immunity. Journal of leukocyte biology, 83(4), 804-816.

16. Mengel, R., Bacher, M., \& Flores-de-Jacoby, L. (2002). Interactions between stress, interleukin-1 $\beta$, interleukin-6 and cortisol in periodontally diseased patients. Journal of clinical periodontology, 29(11), 1012-1022.

17. Moschen, A. R., Kaser, A., Enrich, B., Mosheimer, B., Theurl, M., Niederegger, H., \& Tilg, H. (2007). Visfatin, an adipocytokine with proinflammatory and immunomodulating properties. The Journal of Immunology, 178(3), 1748-1758.

18. Nader, A., Sahar, J., Fariba, S. S., Zohreh, B., \& Adileh, S. (2015). Effect of Non-surgical Periodontal Therapy on Serum and Salivary Concentrations of Visfatin in Patients with Chronic Periodontitis.

19. Nikolopoulos, G. K., Dimou, N. L., Hamodrakas, S. J., \& Bagos, P. G. (2008). Cytokine gene polymorphisms in periodontal disease: a meta-analysis of 53 studies including 4178 cases and 4590 controls. Journal of clinical periodontology, 35(9), 754-767.

20. Nokhbehsaim, M., Eick, S., Nogueira, A. V. B., Hoffmann, P., Herms, S., Fröhlich, H., Deschner, J. (2013). Stimulation of MMP-1 and CCL2 by NAMPT in PDL cells. Mediators of Inflammation, 2013.

21. Ogawa, H., Damrongrungruang, T., Hori, S., Nouno, K., Minagawa, K., Sato, M., \& Miyazaki, H. (2014). Effect of periodontal treatment on adipokines in type 2 diabetes. World journal of diabetes, 5(6), 924-931.

22. Pradeep, A., Raghavendra, N., Prasad, M. R., Kathariya, R., Patel, S. P., \& Sharma, A. (2011). Gingival crevicular fluid and serum visfatin concentration: their relationship in periodontal health and disease. Journal of periodontology, 82(9), 1314-1319.

23. Pradeep, A., Raghavendra, N., Sharma, A., Patel, S. P., Raju, A., Kathariya, R., Naik, S. B. (2012). Association of serum and crevicular visfatin levels in periodontal health and disease with type 2 diabetes mellitus. Journal of periodontology, 83(5), 629-634.

24. Quintero, A. J., Chaparro, A., Quirynen, M., Ramirez, V., Prieto, D., Morales, H., Sanz, A. (2018). Effect of two periodontal treatment modalities in patients with uncon- trolled type 2 diabetes mellitus: A randomized clinical trial. Journal of clinical periodontology, 45(9), 1098-1106.

25. Raghavendra, N., Pradeep, A., Kathariya, R., Sharma, A., Rao, N. S., \& Naik, S. B. (2012). Effect of non surgical periodontal therapy on gingival crevicular fluid and serum visfatin concentration in periodontal health and disease. Disease markers, 32(6), 383-388.

26. Ray, A. (2012). Adipokine leptin in obesity-related pathology of breast cancer. Journal of biosciences, 37(2), 289-294.

27. Saito, T., \& Shimazaki, Y. (2007). Metabolic disorders related to obesity and periodontal disease. Periodontology 2000, 43(1), 254-266.

28. Schilling, E., Wehrhahn, J., Klein, C., Raulien, N., Ceglarek, U., \& Hauschildt, S. (2012). Inhibition of nicotinamide phosphoribosyltransferase modifies LPS-induced inflammatory responses of human monocytes. Innate immunity, 18(3), 518-530.

29. Silness, J., \& Löe, H. (1964). Periodontal disease in pregnancy II. Correlation between oral hygiene and periodontal condition. Acta odontologica scandinavica, 22(1), 121-135.

30. Tabari, Z. A., Azadmehr, A., Nohekhan, A., Naddafpour, N., \& Ghaedi, F. B. (2014). Salivary visfatin concentrations in patients with chronic periodontitis. Journal of periodontology, 85(8), 1081-1085.

31. Todorovic, T., Dozic, I., Barrero, M. V., Ljuskovic, B., Pejovic, J., Marjanovic, M., \& Knezevic, M. (2006). Salivary enzymes and periodontal disease. Medicina oral, patología oral y cirugía bucal. Ed. inglesa, 11(2), 4.

32. Tonetti, M. S., Greenwell, H., \& Kornman, K. S. (2018). Staging and grading of periodontitis: Framework and proposal of a new classification and case definition. Journal of clinical periodontology, 45, S149-S161.

33. Wu, Y., Chen, L., Wei, B., Luo, K., \& Yan, F. (2015). Effect of non-surgical periodontal treatment on visfatin concentrations in serum and gingival crevicular fluid of patients with chronic periodontitis and type 2 diabetes mellitus. Journal of periodontology, 86(6), 795-800.

34. Zhou, S.-S., Da Li, W.-P. S., Guo, M., Lun, Y.-Z., Zhou, Y.-M., Xiao, F.-C., . . Luo, N. (2009). Nicotinamide overload may play a role in the development of type 2 diabetes. World journal of gastroenterology: WJG, 15(45), 5674. 